\title{
Impasses no atendimento e assistência do migrante e refugiados na saúde e saúde mental ${ }^{1}$
}

\author{
Felicia Knobloch* \\ Pontifícia Universidade Católica de São Paulo, Faculdade de Ciências Humanas e da Saúde. São Paulo, SP, Brasil \\ Universidade Estadual de Campinas, Faculdade de Ciências Médicas, \\ Departamento de Saúde Coletiva da Pós-Graduação. Campinas, SP, Brasil
}

\begin{abstract}
Resumo: Questões sobre atendimento à saúde são, atualmente, a porta de entrada dos direitos humanos e dos dispositivos de reconhecimento dos migrantes e refugiados. Entretanto, dependendo de como se entende a assistência a esse grupo pode ser gerado um "desreconhecimento" do sujeito. Impasses surgem ao se naturalizar a experiência migratória como fator de risco que leva à patologia psíquica. Quando o discurso sobre imigração é vinculado a formas específicas de sofrimento psíquico, corre-se o risco de medicalização da experiência migratória e controle farmacológico de problemas que podem ser sociais, políticos ou econômicos. Um desafio é a formação de trabalhadores no atendimento à saúde física e mental dos migrantes para dar suporte ao encontro: é necessário compreender a representação da saúde e da doença no contexto de origem e as especificidades atuais de vida dessas pessoas sem estereotipar a condição de migrante ou refugiado nem silenciar a singularidade do sujeito.
\end{abstract}

Palavras-chave: trauma, migração, saúde mental, etnopsicanálise.

O tema "migração" pode ser considerado um elemento analisador de nossa época. Nos anos de 1970 e 1980 ocorreu o debate sobre a loucura e a psicose, o responsável pelas transformações de teorias e práticas sobre o louco e a loucura. Isso implicou, em 2001, a reforma psiquiátrica e consolidação da política de saúde mental em nosso país, pois colocou em questão paradigmas da psiquiatria vigente. Essa política busca recuperar a condição de cidadão, aprimorar os serviços e estratégias de tratamentos e desenvolver processos de inclusão e inserção de pessoas que sofrem transtornos mentais. Esse estranho, estrangeiro, esquisito, essa alteridade radical que se impunha era vista como perigosa, e por isso sofria segregação, exclusão e precisava ser asilado. Esse "louco", que requisitou seu lugar de sujeito, de cidadão, com seus direitos, que buscou respeito e dignidade na sua forma de existência, conseguiu mudar o estatuto de louco.

Consideramos, então, que esse lugar do estranho, de estranho familiar e estrangeiro que busca reconhecimento em todos os níveis é ocupado atualmente pelos migrantes e refugiados. O difícil trabalho clínico e social por suas especificidades culturais, políticas, sociais e subjetivas nos convocam diretamente para a questão da alteridade, para um Outro que nos coloca em questão tanto nossas práticas de saúde quanto nossas capacidades pessoais, políticas e institucionais de acolhimento do estranho/estrangeiro.

1 Palestra realizada no Simpósio "Desigualdades, Deslocamentos e Políticas Públicas na Imigração e Refúgio" em novembro de 2013.

Agradecimentos: à profa. Dra. Miriam Debieux Rosa pelo convite para participar do Simpósio "Desigualdades, Deslocamentos e Políticas Públicas na Imigração e Refúgio".

* Autora correspondente: feknobloch@gmail.com
Poder legitimar o sofrimento psíquico advindo de várias situações e experiências de vida, tanto de seu lugar de origem como durante o processo de migração, bem como o da inserção ou exclusão no novo lugar, não deveria significar patologização da diferença como a única forma de reconhecimento desse outro estrangeiro. As categorias psicológicas e psiquiátricas que outrora constituíram o discurso da loucura como forma de controle do desconhecido reaparecem hoje na questão dos imigrantes, uniformizando modos de subjetivação singulares. A linguagem psiquiátrica aparece para se colocar no lugar do mal entendido que o encontro com o diferente provoca. Esses mal entendidos dificuldades de comunicação provocados pela diferença de língua e linguagem e diferenças de culturas entre quem cuida e quem é cuidado são alguns dos desafios que precisam ser enfrentados nos atendimentos aos migrantes.

A primeira questão que me surgiu ao ler o título da mesa - Impasses no atendimento e assistência do migrante e refugiados na saúde e saúde mental - é se concordamos com a afirmação ou com a posição de que podemos identificar questões específicas em torno da saúde mental dos migrantes e dos refugiados. A resposta imediata é que sim, principalmente quando compartilhamos das posições da etnopsicanálise e da psiquiatria transcultural como referências às práticas de cuidado.

Marie-Rose Moro (2013), etnopsiquiatra francesa, em sua conferência Psicoterapia transcultural da migração, nos mostrou como a prática em psiquiatria transcultural foi desenvolvida por ela e seus colegas, decorrente dos impasses provocados pelo trabalho com migrantes na França. Pudemos ainda perceber, em seu relato, como a 
prática clínica foi se aprimorando a partir da própria interação dos profissionais com os pacientes. Sem dúvida, a experiência do grupo de etnopsicanálise francesa e de psiquiatria transcultural de Tobie Nathan e Marie-Rose Moro baseada na Etnopsiquiatria de Devereux é, hoje, referência fundamental para o trabalho clínico com os migrantes. Levar em consideração a multiplicidade de contextos, culturas e línguas com que convivem no dia a dia do trabalho, desenvolver estratégias clínicas com capacidade de organizar novos arranjos a cada situação do encontro clínico, considerar a singularidade do sujeito em seu contexto atual com relação a suas referências e especificidades culturais de origem, além de uma forma de organização de trabalho, implica uma posição ético-política do trabalho clínico-institucional.

Entretanto, quando analisamos algumas das recentes produções clínicas, teóricas e técnicas sobre tratamentos em saúde mental de migrantes e refugiados, deparamos com outra posição, que aparentemente não se coloca de forma antagônica à etnopsicanálise e psiquiatria transcultural. Do meu ponto de vista produz outro discurso, que é paradoxal ao tentar inserir a experiência da migração em categorias e transtornos psiquiátricos. Esse discurso apelou para as questões da saúde e condições clínicas através de categorias psiquiátricas para legitimar e dar visibilidade jurídica ao imigrante, ao refugiado e ao asilado, e assim poder inseri-los num sistema onde eles não possuem lugar subjetivo, social, jurídico e político. É justamente pela inserção social ter acontecido por via médico-psiquiátrica que se corre o perigo da naturalização de um discurso patologizante da experiência de migração. Assim, o próprio discurso sobre os cuidados em saúde mental do migrante e refugiado pode contribuir para a criação de alguns impasses que aqui aparecem, e essa discussão não é nada simples.

É muito importante, para entendermos esse processo, analisarmos primeiramente a apropriação da figura do trauma e do traumatismo psíquico. Esse assunto é analisado com profundidade no livro L'Empire du traumatisme, de Fassin e Rechtman (2007), onde os autores discutem a emergência do transtorno do estresse pós-traumático (TEPT) como o modelo médico que impôs uma narrativa a partir de uma certa apropriação política da noção de traumatismo psíquico.

O conceito de transtorno do estresse pós-traumático emerge nos anos de 1970 e é oficializado pelo DSM-III em 1980. Fassin (2007) mostra várias problemáticas advindas da história da concepção da categoria de estresse pós-traumático, mas é interessante entender nesse momento, de modo geral, que tipo de discurso se instaura nessa concepção de traumatismo. Resumidamente, o traumatismo é entendido como um fato, e não como um processo, é uma evidência onde sua realidade não pode ser contestada. A verdade do traumatismo é externa ao campo da clínica, o traumatismo é a prova do intolerável, e o traumatizado é uma vítima. Assim, o evento do traumático se torna o agente etiológico, necessário e suficiente. Dessa perspectiva, o estresse pós-traumático é considerado uma reação normal a uma situação anormal (Fassin, 2007). Reação normal, e não uma doença mental o que constitui um paradigma paradoxal: normalidade de uma condição patológica, normalidade verificável pela presença de sintomas responsáveis pelo sofrimento psíquico. Os sintomas do estresse pós-traumático (TEPT) podem ser organizados em três categorias: (1) sintoma de revivescência, que faz com que os pacientes vivam os eventos traumáticos de forma repetitiva (flashbacks, pesadelos, lembranças recorrentes); (2) sintoma de evitamento e (3) sintoma de hipervigilância.

Através dessa forma de conceber o sofrimento do sujeito, com a categoria de estresse pós-traumático (TEPT) enquanto uma reação normal a uma situação anormal, por meio da qual ao mesmo tempo se afirma um estatuto do trauma e o da vítima, foi possível subsidiar tratamentos psiquiátricos a um contingente de soldados que voltaram da guerra do Vietnã e que viviam com muitas dificuldades para retomar a vida civil. Até então, as manifestações constantes de ansiedade da população de ex-combatentes eram consideradas fraquezas ou resultantes de problemas individuais. Entretanto, o alto número de alcoolistas e de suicídios nessa população obrigou o governo a rever sua posição em relação ao entendimento do sofrimento dos ex-combatentes. Portanto, considerar a guerra como um agente externo que traumatiza e o soldado ser identificado na condição de vítima que sofre o impacto psíquico da violência foi o que permitiu a inclusão desses sujeitos numa condição clínica patológica (normal) de quem sofre de transtornos de TEPT. Como analisa Fassin (2007), o TEPT era o argumento que o governo americano precisava para poder reparar a dívida com o povo americano sobre a guerra do Vietnã nos anos de 1980. O reconhecimento da condição de vítima dado pelo sofrimento foi o que permitiu estabelecer um lugar jurídico para obter reparações financeiras e uma identidade e lugar social (Fassin, 2007). Entretanto, esse lugar social agora é determinado por sua condição clínica (de quem sofre de TEPT), dado por um diagnóstico psiquiátrico que recomenda o tratamento medicamentoso. $\mathrm{O}$ fato de essa situação trazer muitos benefícios a uma população que estava abandonada pelo governo não está em discussão, pois o inédito foi a necessidade de um discurso sustentado pela criação de uma categoria psiquiátrica como única forma de reconhecimento e legitimação de um grupo de sujeitos no meio social.

Não há dúvidas de que algumas pessoas precisam ser medicadas em determinadas situações, quando a angústia ultrapassa o limite do suportável e restringe a vida do sujeito. Não é isto que está em questão, mas o fato de essa posição reforçar ainda mais uma cultura terapêutica de medicalização da existência. Na medida em que a psiquiatria acaba impondo seu saber como uma verdade sobre o sujeito, mantemos a subjetividade excluída do campo de cuidado. A psiquiatria é o saber científico que visa a universalidade, e exclui-se a subjetividade quando, em nome de uma categoria psiquiátrica, não se escuta o sujeito, só os seus sintomas.

$\mathrm{O}$ problema se instaura quando, como consequência de uma política de saúde, a categoria do TEPT se impõe como o único modelo de compreensão de experiências individuais e coletivas ligadas a situações dramáticas 
(D’Halluin, Latté, Fassin, \& Rechtmann, 2004). Como instrumento de gestão da subjetividade, a categoria constitui a resposta necessária para legitimar o vivido, o que acaba por normatizar a experiência de vítimas de guerra e de violências ou de migrações e refúgio.

É interessante chamar a atenção para a história do uso da noção de trauma e sua consequência na concepção da categoria de estresse pós-traumático, pois foi com sua difusão e dentro de sua lógica que os efeitos psicológicos da violência nos refugiados começaram a ser reconhecidos. A categoria de traumatismo psíquico enquanto uma reação normal a um evento anormal serve para embasar uma nova forma de "patologia normal", agora identificada diretamente na condição do migrante. Isto se dá a partir da lógica que reduz a pluralidade de experiências culturais a um modelo único de interpretação biomédico: o de um estresse pós-trauma. É dessa forma que os efeitos traumáticos do percurso da migração entram no discurso clínico, tendo o idealizador da Síndrome de Ulisses, o psiquiatra espanhol Achotegui (2009), enfatizado que "se existe uma área onde os estressores psicossociais possuem uma dimensão quantitativa e qualitativamente relevantes e dificilmente discutíveis desde a perspectiva da saúde mental, essa área é a das migrações do séc. XXI"2 (p. 122, tradução minha). A partir dessa posição, a afirmação da experiência migratória como fator de risco de patologia psíquica justificou a descrição da "Síndrome del Inmigrante com Estrés Crónico y Múltiplo", mais conhecida como Síndrome de Ulisses, categoria nosográfica da psiquiatria que é própria dos que vivem experiência de migração (Achotegui, 2002).

Segundo Achotegui (2009), com o aumento dos deslocamentos humanos, muitos vão adoecer. A intensidade do nível de estresse, que compromete a capacidade de adaptação, será o responsável pela aparição de vários sintomas psíquicos e somáticos. O psiquiatra alerta, então, para o fato de a síndrome do imigrante com estresse crônico e múltiplo se tornar um problema de saúde mental emergente na saúde pública dos países de destino dos imigrantes. Achotegui (2012) considera que a migração em si mesma não é causa de transtorno mental, mas é um fator de risco, já que situações de labilidade ou de hostilidade do meio, que podem impedir a elaboração do luto das perdas vividas, sempre estão presentes. Segundo o psiquiatra, os fatores de risco da síndrome reúnem sete elementos de perda na migração: a da família e amigos, a da língua, a da cultura, a da terra, da posição social, do contato com o grupo de pertença (étnico e religioso) e os riscos pela integridade física. Essas perdas, em geral vivenciadas em situações muito difíceis e limites, não conseguem ser elaboradas. Instala-se um luto extremo que implica um incremento de vulnerabilidade, que, por sua vez, coloca o sujeito em um estado de sofrimento e crise permanente. $\mathrm{O}$ autor insiste que a Síndrome de Ulisses não é uma enfermidade

2 ...si existe un area en la que los estresores psicosociales poseen una dimension cuantitativa y qualitativamente relevante y dificilmente discutible desde la perspectiva de sus relaciones con la salud mental, esa area es la de las migraciones del siglo XXI. mental (pertence ao campo da saúde mental), mas um quadro reativo, e por isso as pessoas devem ser acompanhadas na esfera da prevenção, com abordagem psicossocial do tipo psicoeducativo e de contenção emocional. Enfatiza ainda que a vasta descrição sintomatológica que se faz da síndrome não significa uma atribuição psicopatológica; ao mesmo tempo, demonstra como é inevitável que essas pessoas adoeçam mentalmente e precisem de ajuda específica (Achotegui, 2012).

Para nós, entender a vivência migratória a partir da categoria da Síndrome de Ulisses leva o migrante a um único lugar possível: o de alguém muito vulnerável que irá desenvolver problemas psicológicos que deverão ser medicalizados. Os pressupostos (naturalizados) que embasam essa classificação (a experiência migratória como um fator de risco que induz a uma vulnerabilidade e que desemboca num sofrimento mental) fazem parte do discurso da "cultura terapêutica" (Furedi, 2003). Essa é uma cultura na qual, conforme explicam Cukier, Lavergne e Ragno (2011), "o imperativo terapêutico se tornou cada vez mais potente, veiculando a ideia de um sujeito estruturalmente vulnerável, afetado por um déficit emocional que o torna dependente da expertise terapêutica"” (p. 8 , tradução minha).

Concordamos com Lussi (2013), consultora coordenadora do projeto na Organização Internacional para Migrações (OIM), quando coloca em questão a afirmação de que ser migrante, por definição, significa ser vulnerável. Lussi ainda nos chama atenção para como são as políticas públicas que produzem desigualdades e vulnerabilidades ao favorecerem ou dificultarem o acesso e a garantia aos direitos humanos dos sujeitos que buscam refúgio ou imigração. As experiências de precariedades, de injustiças, de intolerâncias, de violências sofridas pelas políticas de acolhimento inevitavelmente reforçam a vulnerabilidade física e psíquica dessa população (D’Halluin, 2009). Não há dúvidas de que o acesso aos cuidados médicos obedece ao princípio de igualdade dos direitos, mas levar em consideração os efeitos iatrogênicos de políticas públicas com migrantes pode nos permitir o entendimento do sofrimento de algumas situações sem a necessidade da certeza do diagnóstico psiquiátrico.

Chiara Pussetti, antropóloga cultural que desenvolve pesquisas sobre do tema dos imigrantes em Portugal a partir de uma abordagem crítica, é enfática quando ressalta que a representação da vulnerabilidade psicológica enquanto característica intrínseca dos migrantes não leva em consideração as relações entre as questões de exclusão social e de sofrimento individual. Segundo Pussetti (2010):

o esteriótipo do imigrante como pessoa frágil do ponto de vista mental, com um elevado risco de desenvolvimento de patologias psiquiátricas, permite transformar problemas sociais, econômicos e políticos de grupos desfavorecidos em elementos

3 ...l'impératif thérapeutique est devenu toujours plus puissant et central, véhiculant l'idée d'un sujet structurellement vulnérable, affecté par un déficit émotionnel, qui le rend dépendant de l'expertise thérapeutique. 
potencialmente patológicos que podem ser controlados e monitorizados farmacologicamente (p. 94).

A construção de uma categoria nosográfica, a da Síndrome do Imigrante com Estresse Crônico e Múltiplo, como forma de dar conta da vivência da migração, desvia a atenção do contexto político e econômico ao traduzir os conflitos sociais em idiomas psicopatológicos (Pussetti, 2010).

Como aponta a antropóloga, o perigo de que a leitura medicalizante do processo migratório se imponha de forma hegemônica já está instalado. Pussetti (2010) relata que na Europa, pelas dificuldades de avançar na discussão da análise das políticas migratórias e sanitárias que deixam os imigrantes às margens da sociedade, 12 países (Suécia, Áustria, Alemanha, Dinamarca, Grécia, Finlândia, Espanha, França, Irlanda, Itália, Reino Unido, Holanda) mobilizaram-se e estão desenvolvendo um projeto financiado pela Comissão Europeia - Health and Consumer Protection DG (SANCO) - sobre questões de problemas de saúde mental dos imigrantes, principalmente para que haja intervenção farmacológica dessa população e criação de "serviços de saúde mental culturalmente sensíveis" (Pussetti, 2010). Entretanto, como ressalta Pussetti (2010), pela pouca reflexão sobre a forma como se organiza a política pública migratória, não se analisa a possibilidade de que a própria política pode se tornar um fator de risco e patologia, que vai produzir efeitos iatrogênicos nos serviços.

Consideramos a Síndrome de Ulisses como representante do discurso da ideologia biomédica, que domina nossa cultura. Na análise de Pussetti (2010), a síndrome busca estereotipar a experiência migratória, onde as vivências emocionais, que são individuais e heterogêneas, são vistas de forma homogênea, e as categorias diagnósticas eliminam as diferenças do estranho/estrangeiro, anulando as singularidades. Torna-se uma política, política clínica e terapêutica interpretar a priori a instabilidade da vida do imigrante como anomalia e potencial psicopatológico, sem levar em consideração o contexto, a história do sujeito e as condições sociais e políticas a que são submetidos no país de acolhimento. Em nome da busca de especificidades clínicas e terapêuticas dos traumas psíquicos dos que pedem asilo, dos refugiados e dos imigrantes em geral, o desenvolvimento de questionários padronizados centrados na categoria TEPT acabam simplificando a complexidade da experiência subjetiva. Utilizar protocolos de diagnósticos e de tratamento que em geral, como aponta Pussetti, pressupõem pacientes "padrão" e ocidentais, vai produzir respostas fora do esperado e reforçar várias teorias psis, não por avaliarem as condições dos sujeitos, mas por eles serem os "fora da norma". Quando se pensa que a medicação de pacientes é apoiada nesses protocolos, pergunta-se o que pode acontecer quando não se leva em consideração o fato do paciente ser de outra cultura e ter outras referências. Como enfatiza a antropóloga na leitura patologizante ou medicalizada da diferença cultural, as características desses grupos vão acabar se tornando elementos potencialmente patológicos. É importante sublinhar que "nem sempre os modelos médicos fazem sentido para as experiências pessoais dos doentes" (p.101) justamente pelas diferenças culturais entre médicos e imigrantes nos modos de definir e agir, como disse Pussetti (2010). A medicalização da condição do migrante no sentido que lhe dá a teoria da Síndrome de Ulisses, segundo Lechner (2007), omite o essencial da compreensão da experiência dos imigrantes: "reconhecer como cada história, cada migrante, cada caso clínico tem um sentido particular e único, sendo esse o sentido e não outro que pede uma escuta e ajuda" (p.85).

Em tempos de medicalização da existência, parece que a saída mais reconhecida e fácil, mais rápida e menos angustiante, é a de se medicar o que não se compreende, o desconfortável. Medicar e atribuir uma patologia é partilhar de uma identidade (postiça, porém referendada pela cultura científica) entre as pessoas, mantendo a ilusão do conhecido. Sem negar a importância da medicação de forma adequada, enfatizamos que o desconforto causado pelo reconhecimento da inoperância de nossas estratégias clínicas com pessoas de outras culturas, que tem vivências e experiências de violências inimagináveis, não pode ser aplacada com a redução de suas vivências a leituras "patologizantes" das experiências, a quadro clínicos e doenças mentais que podem ser medicadas.

É por isso que o desafio é cuidar da formação de profissionais da saúde, para que uma educação permanente em saúde ocorra e para que o objetivo esteja além de só capacitar os trabalhadores a se relacionarem com pessoas provenientes de outros contextos culturais. O desafio é uma formação que permita aos profissionais (inclusive aos médicos) ampliar os modos de cuidar e agregar ao modo dominante outras referências, de forma que não se homogeneízem vivências e sofrimentos dos imigrantes para que não se reproduzam atitudes universalistas, organicistas, biomédicas e de abordagens psicológicas reducionistas. Um espaço que possa introduzir outros olhares e legitimar teorias não hegemônicas; valorizar as práticas e saberes terapêuticos que os imigrantes trazem com eles, sem traduzir ao idioma biomédico. Buscar estratégias clínico-institucionais abertas ao diálogo com a diferença. É um grande desafio político, clínico e pedagógico proporcionar este tipo de formação. Além de introduzir novos paradigmas que vão definir novos saberes e práticas para desenvolver novas competências clínicas (culturais e interculturais), isto implica um deslocamento pessoal para se apropriar de outras racionalidades, o que pode levar a uma desestabilização das certezas absolutas, nada agradável ou fácil.

Na realidade, os desafios são inúmeros. Como enfrentar o impasse que a oferta de assistência à saúde do imigrante e refugiado nos coloca? Como oferecer assistência sem que se resuma a um modo de adaptação à nova cultura pela nomeação e classificação de sintomas e diagnósticos onde estas intervenções podem constituir formas normativas de subjetividade? Como cuidar para que as dimensões assistenciais clínicas não imponham práticas e critérios biomédicos que ignorem os valores e interpretações do imigrante sobre seu próprio sofrimento? Como perceber o 
limiar entre a oferta de cuidado e a tendência pedagógica de afiliar o paciente imigrante à normalidade dada pelos valores ocidentais e saberes que se impõem como dominantes? (Stengers, 2001). Como introduzir uma formação aos profissionais de saúde, sabendo que o encontro entre mundos culturais diversos, nas palavras de Lechner (2005), "nunca é privado de conflitos e não gera necessariamente simpatias e (re)conhecimentos mútuos" (p.17)?

Reconhecer o desafio é muito importante, pois nos mostra como a tarefa de formação de uma equipe multidisciplinar "culturalmente sensível" não é nada fácil, além de demandar muito tempo. Quando nos damos conta de como a formação para o trabalho em saúde com migrantes pode implicar um longo processo de mudanças da práxis clínica e de valores, tememos ainda mais o reforço da adesão à posição de medicalização da experiência migratória. Se isto acontece, medicar deixa de ser apenas um instrumento para auxiliar o sujeito a superar o sofrimento e passa a ser a única estratégia clínica, por ser considerada uma resposta mais rápida. Realmente deparamos com um grande impasse, que teremos de enfrentar. A saída está em investir na formação de pessoas que possam compreender a experiência de mal estar dos imigrantes, devolvendo-lhes a dignidade sem patologizar a diferença e sem negar o sofrimento. Isso pode fornecer um outro lugar e, quem sabe, outro destino, ao sujeito estrangeiro que vem em busca de novos territórios de existência.

\section{Impasses in the care and support of immigrants and refugees in health and mental health}

Abstract: Issues on health care are currently the starting point to defending human rights and recognition devices of immigrants and refugees. However, depending on how the assistance to this group is understood, it can become a tool for 'unrecognizing' the subject. Impasses arise in understanding the migratory experience as a natural risk factor that leads to psychopathology. When the discourse on immigration is connected to specific forms of psychological distress, one takes the risk of medicalizing immigration and exerting a pharmacological control over problems that, in reality, might belong to social, political or economic order. It is a challenge to train employees for the care of mental and physical health of immigrants to support the meeting: it is necessary to understand the representation of health and disease in the original context and the current particularities of their lives without stereotyping the condition of immigrant of refugee or mute the singularity of the subject.

Keywords: trauma, migration, mental health, ethnopsychoanalysis.

\section{Impasses au niveau des soins médicaux et en santé mentale du migrant et des réfugiés}

Résumé: Actuellement, les questions sur les soins médicaux des migrants et des réfugiés représentent une voie d'accès aux droits humains et à la reconnaissance de ce groupe. Toutefois, la manière dont se pratique l'assistance peut occasionner une «mé-reconnaissance» du sujet. Des impasses apparaissent lorsque l'expérience migratoire est envisagée comme facteur de risque naturel d'une pathologie psychique. Quand le discours sur l'immigration est lié à des formes spécifiques de souffrance psychique, il y a un risque de médicalisation de l'expérience migratoire et de contrôle pharmacologique de problèmes qui peuvent être d'ordre social, politique ou économique. Il est nécessaire d'investir dans la formation des professionnels chargés de la santé physique et mental des migrants pour soutenir le rencontre ait lieu: il faut tenir compte de la représentation de la santé et de la maladie dans le contexte d'origine, ainsi que les spécificités actuelles de la vie de ces personnes, sans stéréotyper la condition de migrant ou de réfugié et sans bâillonner la singularité du sujet.

Mots-clés: traumatisme, migration, santé mentale, ethnopsychanalyse.

\section{Obstáculos en la asistencia sanitaria y atención a la salud mental de inmigrantes y refugiados}

Resumen: Las cuestiones sobre la asistencia sanitaria de los inmigrantes y refugiados son consideradas actualmente como puerta de entrada a los derechos humanos y una manera de reconocimiento de este grupo. Sin embargo, según como se entienda la asistencia a este grupo, se puede llevar a un "des-reconocimiento" del sujeto. Los impedimentos surgen al naturalizar la experiencia migratoria como factor de riesgo que causa la patología psíquica. Cuando el discurso sobre inmigración se vincula a formas específicas de sufrimiento psíquico, pone en riesgo de medicalización la experiencia migratoria y control farmacológico de problemas que pueden ser de orden social, política o económica. Un desafío es el de la formación de trabajadores para la atención sanitaria física y mental de los inmigrantes para apoyar el encuentro: sin estereotipar la condición de migrante o refugiado ni silenciar la singularidad del sujeto, es necesario entender la representación de la salud y la enfermedad en el contexto de origen y las particularidades actuales de la vida de esas personas.

Palabras clave: trauma, migración, salud mental, etnopsicoanálisis. 


\section{Referências}

Achotegui, J. L. (2002). La depresión en los inmigrantes: una perspectiva transcultural. Barcelona: Editorial Mayo.

Achotegui, J. L. (2009). Estrés límite y salud mental: el síndrome del inmigrante con estrés crónico y múltiple (síndrome de Ulises). Gaceta Médica de Bilbao, 106(4), 122-133. Recuperado de http://www.sciencedirect.com/ science/article/pii/S0304485809746657

Achotegui, J. L. (2012, enero). La crisis como factor agravante del Síndrome de Ulises (Síndrome del duelo migratório extremo). Temas de Psicoanálisis, 3. Recuperado de http://www.temasdepsicoanalisis.org/la-crisis-comofactor-agravante-del-sindrome-de-ulises-sindrome-delduelo-migratorio-extremo1/

Cukier, A., Lavergne, C., \& Ragno, V. (2011). Des violences extrêmes aux violences quotidiennes: approche clinique de la notion du traumatisme. Sciences-Croisées, 9. Recuperado de http:/www.sciences-croisees.com/N9/ Cukier-Lavergne-Ragno.pdf

Fassin, D., \& Rechtman, R. (2007). L'empire du traumatisme: enquête sur la condition de victime. França: Flammarion.

Furedi, F. (2003). Therapy culture: cultivating vulnerability in an uncertain age. New York: Routledge.

D’Halluin, E. (2009). La santé mental des demandeurs d'asile. Hommes et Migrations, 1282/2009, 66-75. Recuperado de http://hommesmigration.revue.org/447

D’alluin, E., Latté, S., Fassin, D., \& Rechtman, R. (2004). La deuxième vie du traumatisme psychique. Revue française des Affaires sociales, 2014/1(1), 57-75. Recuperado de http://www.cairn.info/revue-francaise-des-affaires-sociales2004-1-page57

Lechner, E. (2005). Imigração e saúde mental: o sofrimento dos migrantes e o encontro de ordens simbólicas. Psilogos, 2(2), 15-19. Recuperado de http://www.psilogos.com/ Revista/Vol12N2/Indice4_ficheiros/Lechener.pdf

Lechner, E. (2007). Imigração e saúde mental. Revista Migrações (número temático imigração e saúde), 1, 79101. Recuperado de http://www.ceg.ul.pt/migrare/publ/ migracoes1_completo.pdf

Lussi, C. (2013). Políticas públicas e desigualdades na imigração e refúgio. In Simpósio Desigualdades, deslocamentos e políticas públicas na imigração e refúgio. São Paulo.

Moro, M.R. (2013). Psicoterapia transcultural da migração. In: Simpósio Desigualdades, deslocamentos e políticas públicas na imigração e refúgio. São Paulo.

Pussetti, C. (2010). Identidades em crise: imigrantes, emoções e saúde mental em Portugal. Saúde e Sociedade, 19(1), 94-113. Recuperado de http://dx.doi.org/10.1590/S010412902010000100008

Stengers, I. (2001). Le laboratoire de l'ethonopsychiatrie. In T. Nathan. Nous ne sommes pas seuls au monde. Paris: Le Seuil.

Recebido: 12/05/2014

Revisado: 17/06/2014

Aceito: 25/07/2014 